\title{
MELHORANDO SEU DOCUMENTO
}

\author{
J.B.Sousa ${ }^{1}$ \\ F.Levi2 \\ I.K.Sonoki² \\ B.U.Silva ${ }^{2}$
}

(Adaptação livre do Capítulo Introdutório do "Guide to the Perfect Document" de Hobbit Coward, encarte do P C Magazine, Ziff-Davis UK Limited, setembro 1993)

\section{INTRODUÇÃO}

Diferenças na escolha dos caracteres tipográficos afetam a comunicação, moldando as mensagens que queremos transmitir. 0 julgamento consciente e, principalmente, o julgamento inconsciente de um trabalho dependem desta escolha, que influi na eficiência de uma apresentação escrita.

O Uso da editoração pode transformar seu poder de comunicação pela ação de um processador de textos eficiente, um DTP (Desktop Publishing). Manipulando caracteres (fonts) de múltiplos tamanhos, o resultado se assemelha muito mais à produção da imprensa profissional do que ao de uma antiga máquina de escrever. Com um pouco de conhecimento de onde se quer chegar e do poder da nova ferramenta DTP, a produção pode atingir a qualidade almejada em seu computador e impressora.

\section{OBJETIVOS TIPOGRÁFICOS}

O objetivo inicial, e principal, é criar um ar profissional. Não ceda à tentação de usar toda a riqueza de tipos disponível. A existência de diferenças tipográficas se destina à

\footnotetext{
${ }^{1}$ Departamento de Mineralogia e Petrologia, Instituto de Geociências, USP.

2Departamento de Geologia Geral, Instituto de Geociências, USP.
} 
comunicação visual que mais se ajusta à mensagem, e não à ostentação de múltiplos recursos. Tente restringir-se para não prejudicar o conteúdo pela exaltação da forma - um bom assunto, nos faz esquecer do documento.

Ao iniciar a produção de um documento coloque-se na posição do leitor. Esquematize cada página como se estivesse escrevendo para sua própria leitura. Não se pode obrigar ninguém a ler, mas o texto pode ser o menos hostil e possuir o máximo de clareza, para ser folheado e navegado pelo leitor, destacando cada seção.

Pode parecer estranho - já que queremos que o leitor leia tudo - mas geralmente passamos os olhos sobre um documento, antes que as suas partes possam deter maiores atenções. Capturando a atenção inicial, fica mais fácil dirigir nossas palavras à memória do leitor do que, simplesmente, fazer com que um documento vá para o lixo do esquecimento (veja abaixo, "Fundamentos da Legibilidade").

\section{VEJA E SINTA}

O leitor tem idéias próprias de como deveriam se apresentar os mais variados tipos de documentos, com base tanto em experiência própria como em normas aceitas. Bem antes de ler, terá tentado fixar o jeito do documento como um todo - inconscientemente ou não - fechando-o, ou não, dando muito peso à aparência.

Só os livros - e nem sempre - são lidos de fio a pavio. Mais freqüentemente, o olhar procura o que chama a atenção - ou pela espectativa, ou pelo inusitado - num cabeçalho, título ou listagem; ou então pelos tipos, tamanhos e ênfases.

O designer-Ihe dá a oportunidade de enfatizar pontos do documento usando estilos, rostos, tamanho do ponto, figuras, tabelas, ilustrações, títulos, puxando cotas e sombreados.

\section{ESTRUTURA DE ACESSO}

Antes de escrever, considere o que o leitor teria a ganhar com o texto - é o que a maioria exige antes de ler atentamente. Feito isso, passa-se às seções relevantes ou ao corpo do texto em detalhe. A facilidade com que isso será feito é função de uma estrutura de acesso.

Ela é constituída pelo índice, articulado a cabeçalhos e outras artimanhas que facilitam a navegação, dizendo o que, onde e quem escreveu. Em outras palavras, bem mastigado é mais fácil de digerir. Nos textos mais longos isso se torna crucial. Se os conjuntos de partes superarem a meia dúzia devem ser numerados para possibilitar um fácil acesso. Os processadores de texto automatizam estilos e listas os quais, por sua vez, automatizam estas tarefas com estruturas e formas atraentes e expressivas para indicar os destaques. 


\section{NUMERAÇÃO DE PÁGINAS}

Trata-se de boa prática se houver mais de duas páginas, e se for mais de quatro e o documento abordar mais de dois temas, também deve constar um índice para localizar pontos relevantes, seções, subseções, tabelas, ilustrações e notas de rodapé.

Os sistemas de numeração de cada tipo de indicação devem ser distintos, como usando números para cabeçalhos e letras para ilustrações. Relatórios, em particular, devem permitir a quem os consulta uma localização rápida e bem sinalizada - não é aconselhável uso de números romanos longos (como por exemplo, $\mathrm{CMCCIC}$ ) difícilmente enumeráveis. Bons processadores de texto enumeram e renumeram facilmente. Não dispondo desta facilidade use um número genérico tipo " $x x "$, a ser substituído na revisão final, que garanta uma seqüência sem falhas.

As funções de procura (search) e substituição (replace) devem ser usadas para assegurar que todas as ocorrências alheias ao assunto sejam localizadas.

\section{FOLHAS DE ESTILO}

As folhas de estilo (Style sheets) e etiquetas (Tag) são funções dos processadores de texto ou pacotes DTP, que podem parecer místicas, mas são, tão somente, conjuntos de instruções que se destinam a aliviar o trabalho de formatação. Tipicamente elas armazenam os tipos e tamanhos de caracteres, margens, espaçamentos, distâncias entre linhas, tabulações, negritos, itálicos, sublinhados, etc, de seu texto. A cada coleção corresponde um uso costumeiro e um nome com códigos de controle de teclado a ser programado. Configuram-se assim estilos que permitem facilmente obter formatações amplas e consistentes num documento como um todo.

Outra vantagem é a substituição. Se necessário, ela é aplicável com extrema facilidade para, por exemplo, substituir todos os sublinhados por negritos. Caracterizado um estilo, mesmo diferente, ele pode ser (re)programado com facilildade nos processadores de texto mais recentes.

Muitos consideram que as folhas de estilo dão mais trabalho do que ajuda. Quando alguém tiver reaplicado formatações inúmeras vezes e, pior, quando tiver de modificá-las mais de uma vez, perceberá a utilidade das folhas de estilo (Style sheets). A consistência em coleções de documentos e as exigências de editoração tornam isso ainda mais claro.

\section{FUNDAMENTOS DA LEGIBILIDADE}

Quase todas as impressoras a laser e programas com fontes escalonáveis são providas dos tipos Times Roman e Helvetica ou seus equivalentes. Assim o Windows 3.1 usa Times New Roman e Arial, e a LaserJet III e o 4CG usam Times e Univers. As saliências na base do 'A' na 


\section{Times New Roman} Helvetica Regular Gill Sans Futura Book

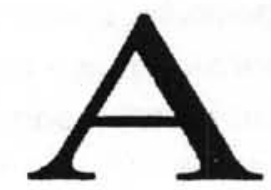

serif

sans sertt

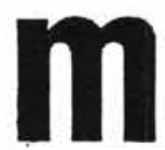

For line spacing you should cry to use one point higher than for the text. If you have a package that supports leading set the line spacing to $10 \%$ of die point size.

Adobe Gentmond asoprs

Goudy Old Style has a much lower $x$-height than, say, Times Roman as shown in the example here $=$

$$
\text { xholgh }
$$

alinhamento horizontal das letras num corpo de texto. 'Sans serif' (sem serifs) são melhores em textos curtos como cabeçalhos, notas de rodapé, tttulos, etc (veja figura ao lado). Inversões destes papéis podem ocasionalmente ser usadas para chamar a atenção destacando trechos, desde que $\circ$ uso seja cuidadosamente combinado com os espaçamentos, para manter a facilidade de ler. Freqüentemente supomos que o justificado é o "certo", mas de fato ele pouco aumenta a legibilidade. A hifenação propiciada pelos pacotes DTP nem sempre resolve os problemas de vazios; o "ensaio e erro" é às vezes a melhor solução. Pode-se, às vezes, evitar que as letras se espalhem desmazeladamente pela página, determinando um espaçamento mínimo entre letras igual a zero.

0 espaçamento entre linhas (leading) deve em geral ser maior do que aquele entre palavras, e aquele entre letras deve ser o menor. Porém, obedecido isso, os parâmetros podem, em princípio, ser variados a seu gosto e critério, ou seguindo seu pacote DTP.

Para que textos longos sejam menos cansativos, eles não dever superar os 70 caracteres por linha. No caso de menos de uns $\mathbf{5 0}$, os textos obrigam a lidar com irregularidades como a separação de linhas por hifenação. No caso de mais do que 70 , o leitor pode "peder a linha" (iteralmente).

Num relatório, 10 ou 11 pontos é um bom tamanho. 0 espaçamento entre linhas, o leading deve ser uns $10 \%$ a mais, um pouco maior se as linhas são muitos longas. Observe que como a altura de um ' $x$ ' Goudy Old Style é bem menor do que em Times Roman. Coisas assim nos levam a comparar trechos impressos em estilos diferentes para julgar a legibilidade relativa.

\section{HIFENAR, JUSTIFICAR E ALINHAR}

Os alinhamentos mais usados são o justificado, que alinha à direita e esquerda, e o alinhamento à esquerda que deixa o lado direito irregular. Freqüentemente achamos que o certo é justificar, mas isso nem sempre aumenta a legibilidade dos textos. O pacotes DTP podem hifenar mas forçam às vezes dando aspecto desagradável na impressão.

Uma carta, memorando ou fax não devem conter texto justificado. Por mais que seja rebuscado o produto do teclado, torná-lo justificado é trabalhoso demais, pois os parágrafos 
costumam ser curtos retirando a flexibilidade das alternativas. Além disso poucos processadores são muito flexíveis no que concerne espaçamentos entre letras e palavras.

Um pouco de hifenação é imprescindivel quando as colunas são muito estreitas. Texto alinhado à direita é usado ocasionalmente em paginações em que se usa uma legenda à esquerda de uma ilustração.

\section{PARÁGRAFOS}

Para indicar o início de um parágrafo, ou se usa a tecla de tabulação ou se coloca meia ou uma linha entre um parágrafo e outro. Uma tabulação menor é o que basta em parágrafos com colunas estreitas.

\section{COMPUTADORES NÃO SÃO MÁQUINAS DE ESCREVER}

A HP LaserJet como impressora revolucionou a apresentação editorial em PCs. Emular uma máquina de escrever ficou logo coisa do passado, substituída por espaçamentos proporcionais com tipos regulares nos mais variados estilos de editoração colocados ao alcance de todos. Os processadores Word e WordPerfect levaram a tecnologia a se articular ao desktop dos PCs tanto com às impressoras, aumentando a flexibilidade. Nos anos noventa, a tecnologia TrueType também se soma à flexibilidade. Há que se considerar também as constribuições de Adobe Type Manager (ATM) for Windows, OS/2 e Macintosh, que fazem com que espaçamento único seja aceitável só para os documentos mais simples.

Entretanto ainda há disponibilidade de fontes tipo Curier em todos os sistemas de editoração de palavras (DTP) e impressão por computador. A razão pela qual esta fonte ainda está disponível, é porque ainda existem pessoas que gostam de usá-la. Afinal de contas, houve uma época em que todas as correspondências eram escritas à máquina. Como tal, o aspecto do produto escrito à máquina transmitiu um ar de formalidade que não se extinguiu completamente. Freqüentemente o texto datilografado é usado em correspondências para manter o sentido de um documento menos formal do que um relatório de empresa.

O uso combinado de espaçamento, alinhamento e justificação, junto com negrito e itálico em Times e Helvetica faz pensar em outros requintes de acabamento, distanciando a velha máquina de escrever. Como tal o usuário deveria aplicar as regras do tipógrafo ao invés das regras do datilógrafo para o seu documento.

Há certas coisas, consideradas como normas quando se usa máquina de escrever, que não se aplicam quando se usa as ferramentas atuais de criação de documentos.

..A utilização de espaçamento duplo após o término da sentença. Isto é desnecessário, pois se deve usar apenas um espaço. 
..As aspas duplas e as simples não devem ser usadas. Ao invés disto, usam-se ferramentas, como o mapa de caracteres do Windows ou de outro aplicativo, para descobrir como criar aspas tipograficamente corretas. Para traços longos (-) você deve tentar usar o caracter correto, uma vez que o uso de dois sinais de subtração (--) freqüentemente deixa um espaço feio entre eles, quando da impressão.

Using proportionslly-spaced typefaces such as Times rogulres you to pery attep. tion to how the finishod document should look.

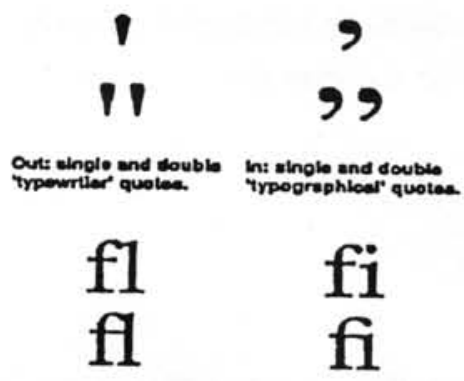

Ugatures (bottom) loak smarter then ordinery

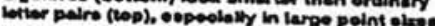

..Não utilize sublinhado. Não é apenas ultrapasado, mas também reduz a legibilidade. Ao invés disto, utilize Itálico ou Negrito.

Estas coisas são fundamentais. Considere a criação de um estilo próprio - para você, seu grupo, firma, etc. Usuários mais avançados talvez possam investigar a utilização de ligaduras (veja ao lado). $O$ único problema neste caso é que a maioria dos programas DTP ou processadores de texto podem não suportá-las automaticamente - apenas 0 Pagemaker, QuarkXPress, Ventura Publisher e WordPerfect o fazem e mesmo assim, através da utilização de tipos destinados a profissionais, só disponiveis no sistema de impressão PostScript. 